\title{
Patient motives for contacting out-of-hours care in Denmark: a cross-sectional study
}

\author{
Linda Huibers $^{1 *}$ (D), Anders H. Carlsen ${ }^{1}$, Grete Moth ${ }^{1}$, Helle C. Christensen ${ }^{2,3}$, Ingunn S. Riddervold ${ }^{4}$ and \\ Morten B. Christensen ${ }^{1}$
}

\begin{abstract}
Background: Patients in need of acute health care do not always contact the most suitable health care service provider. Contacting out-of-hours primary care for an urgent problem may delay care, whereas contacting emergency medical services for a non-urgent problem could ultimately affect patient safety. More insight into patient motives for contacting a specific health care provider may help optimise patient flows. This study aims to explore patient motives for contacting out-of-hours primary care and the emergency medical services in Denmark.

Methods: We conducted a cross-sectional observational study by sending a questionnaire to patients contacting out-of-hours primary care and emergency medical services, both of which can be directly contacted by patients, in two of five Danish regions in 2015. As we aimed to focus on the first access point, the emergency department was not included. The questionnaire included items on patient characteristics, health problem and 26 pre-defined motives. Descriptive analyses of patient characteristics and motives were conducted, stratified by the two health care service providers. Factors associated with contacting each of the two service providers were explored in a modified Poisson regression analysis, and adjusted risk ratios were calculated.
\end{abstract}

Results: Three key motives for contacting the two service providers were identified: 'unpleasant symptoms', 'perceived need for prompt action' and 'perceived most suitable health care provider'. Other important motives were 'need arose outside office hours' and 'wanted to talk to a physician' (out-of-hours primary care) and 'expected need for ambulance' and 'worried' (emergency medical services). Higher probability of contacting the emergency medical services versus out-of-hours primary care was seen for most motives relating to own assessment and expectations, previous experience and knowledge, and own needs and wishes. Lower probability was seen for most motives relating to perceived barriers and benefits.

Conclusions: Patient motives for contacting the two health care service providers were partly overlapping. The study contributes with new knowledge on the complex decision-making process of patients in need of acute health care. This knowledge could help optimise existing health care services, such as patient safety and the service level, without increasing health care costs.

Keywords: After-hours care, Primary health care, Emergency medical services, Help-seeking behaviour, Motivation, Patient safety, Emergency medicine

\footnotetext{
* Correspondence: huibers@ph.au.dk

${ }^{1}$ Research Unit for General Practice, Bartholins Alle 2, 8000 Aarhus, Denmark

Full list of author information is available at the end of the article
}

(c) The Author(s). 2020 Open Access This article is licensed under a Creative Commons Attribution 4.0 International License, which permits use, sharing, adaptation, distribution and reproduction in any medium or format, as long as you give appropriate credit to the original author(s) and the source, provide a link to the Creative Commons licence, and indicate if changes were made. The images or other third party material in this article are included in the article's Creative Commons licence, unless indicated otherwise in a credit line to the material. If material is not included in the article's Creative Commons licence and your intended use is not permitted by statutory regulation or exceeds the permitted use, you will need to obtain permission directly from the copyright holder. To view a copy of this licence, visit http://creativecommons.org/licenses/by/4.0/ The Creative Commons Public Domain Dedication waiver (http://creativecommons.org/publicdomain/zero/1.0/) applies to the data made available in this article, unless otherwise stated in a credit line to the data. 


\section{Background}

Recent years have seen an increase in the number of contacts to the acute health care services. Crowding of patients at emergency departments (EDs), excessive demands on the emergency medical services (EMS) [1-3] and more frequent use of out-of-hours primary care are widespread in many countries [4]. The high demand may have several negative effects: high use of resources, increased health care costs and high workload for health care professionals. This development may further cause higher risk of errors, longer waiting times for patients and potential treatment delay, and lower job satisfaction [1, 5-11].

When experiencing a health problem, a patient is likely to request prompt medical assessment and may thus decide to contact a specific health care service. Apart from the specific health problem, other motives can influence the decision to contact a health care service outside office hours. Worry and a perceived urgent need to see a general practitioner (GP) are frequently mentioned as motives for contacting out-of-hours primary care-, but perceived lack of availability and accessibility of own GP also seems to play a role [12]. Prevention or ruling out of serious disease is another important motivation, specifically in parents of children [13]. Worrying and anxiety have also been identified as important motives for contacting EMS and EDs [3, 14]. The prospects of receiving fast help and getting easy access to diagnostic tests are known motives for contacting the ED, as are symptoms perceived as being too severe for assessment in primary care [14-17].

Two options for getting health care outside own GP's office hours are offered in several countries: calling outof-hours primary care or dialling the national emergency number (1-1-2 in Europe, 9-1-1 in the USA). The choice between these two should be based on the urgency level of the experienced health problem, but many other factors influence the patient's decision. Consequently, patients do not always contact the most relevant health care service [12, 18-23] and thus do not get the most suitable care. Contacting primary care for an urgent health problem may delay the care and worsen the condition, whereas contacting the EMS for a non-urgent problem may ultimately affect patient safety outcomes due to work overload and overtreatment; this may also result in unnecessary use of resources.

More insight into patients' motives for choosing specific out-of-hours health care services is important as new knowledge in this field could be used to make suitable adjustments of the existing health care services and to develop initiatives guiding the patients in choosing the most relevant service for their health problem. This may ultimately help reduce the workload in the out-ofhours health care services and increase the service level through better management of patient safety and reduced delay in the care for severely ill patients.

\section{Methods \\ Aim}

The aim of this study was to explore patient motives for seeking acute health care at out-of-hours primary care and the EMS and to investigate motives associated with contacting each of these two health care service providers.

\section{Design and setting}

We conducted a cross-sectional observational study to explore patients' motives for contacting out-of-hours care by sending a questionnaire to patients who had contacted out-of-hours -primary care and the EMS. Data was collected in two Danish regions, the Capital Region of Denmark in Copenhagen and the Central Denmark Region, during a two-week period in February-March 2015.

All citizens with fixed abode in Denmark are listed with a GP and have access to the public (tax-funded) health care system free of charge. GPs serve as gatekeepers to secondary care and are usually available on weekdays from 8 am to $4 \mathrm{pm}$. Denmark is divided into five regions; each of these regions is responsible for organising health care in their own region. Health care is provided by primary care (both daytime and -out-ofhours primary care), the EMS and secondary care (e.g. hospitals, EDs). Referral from either primary care or the EMS is required before an ED visit or hospital admission. Therefore, we did not include the ED. Direct use (i.e. self-referring) to out-of-hours primary care and the ED is low in Denmark, due to required telephone access.

In the Central Denmark Region, out-of-hours primary care is organised by GPs in large-scale cooperatives (GPCs). GPs perform telephone triage and deal with the presented problem by giving telephone advice or by referring the patient to a subsequent face-to-face consultation [24]. In Copenhagen out-of-hours primary care is an integrated part of the EMS, with medical helpline 1813 (MH-1813) serving as a dedicated entrance for non-urgent cases. Nurses perform the triage; they are supported by a computerised decision-support tool and the opportunity to consult a doctor (or hand over the call), but these doctors may also answer direct calls. Patients receive telephone advice or are referred to a faceto-face consultation.

In both regions, the EMS consists of an emergency medical coordination centre (EMCC) handling all 1-1-2 emergency calls. The EMCC is staffed by different types of health care professionals (nurses, paramedics and doctors for supervision), who asses the urgency level and decide on the suitable response, as indicated by the 
criteria-based dispatch protocol named the Danish Index for Emergency Care [25]. This protocol states 37 main dispatch criteria (symptoms) and divides calls into 5 levels of emergency.

\section{Study population}

We included patients who contacted out-of-hours primary care or the EMS outside office hours (i.e. weekdays from $4 \mathrm{pm}$ to $8 \mathrm{am}$, entire weekends and bank holidays), either themselves or by another person. The first contact with a health care professional within the study period was included for each patient. If a patient had a followup contact with the other out-of-hours health care service provider within the study period, we included only the first contact. Exclusion criteria were: contact during daytime, death at the time of dispatching questionnaires, address protection, living in an institution, tourists and other citizens with an invalid personal identification number (PIN) [26] and participation in one of the pilot studies. Patients aged 13-18 years were also excluded for confidentiality reasons. Moreover, for EMS contacts, we excluded patient transport 'planned in advance' and requests for an acute ambulance by health care professionals. Contacts with a bystander calling were also included, which is assessed more common for EMS contacts. A recorded message on the telephone waiting line informed patients calling the GPC and $\mathrm{MH}-1813$ about the ongoing research project, and callers were given the opportunity to decline participation by pressing ' 9 '.

\section{Development of questionnaire}

First, a literature search was conducted, and existing questionnaires on patient motives were studied, resulting in an overview of factors related to decision-making in patients and prevailing motives for contacting out-ofhours care. Next, these factors and motives were categorised into a model for decision-making when contacting out-of-hours health care services. The model was based on Andersen's Behavioural Model [27] and adapted to the Danish health care system. Several internal research meetings and an external expert feedback round were held, resulting in the final questionnaire (Additional file 1). Motives were measured by 26 predefined statements relating to the decision to contact outof-hours care (Additional file 2). Respondents were asked to rate, on a 5-point Likert scale, the importance of each statement for the decision. Motives were grouped into: 'own assessment and expectations', 'barriers and benefits', 'previous experience and knowledge', and 'needs and wishes'. We tested the questionnaire twice in the GPC waiting room and interviewed four patients in a general practice waiting room to ensure clarity and validity. Moreover, three small-scale pilot studies were conducted to enhance clarity, increase the response rate and enable a power calculation.

The final questionnaire included questions on patient characteristics, the health-related problem and the patient's motives for contacting out-of-hours care. Patient characteristics included: age and sex, decision maker (patient himself/herself, family member, other known person or unknown person), ethnicity and marital status. Questions about the health-related problem included: main problem and duration. In addition, we included information extracted from the patient registration systems of the out-of-hours health care service providers: date and time of contact, patient's PIN, type of contact and urgency level (only for EMS contacts). The PIN was used to calculate age and sex, search for duplicates and check the patient's status (possible death) before sending the questionnaires.

\section{Data collection}

A power calculation showed that we needed a study population of 400 respondents per health care service provider, each consisting of two units, to be able to detect a $10 \%$ difference in the importance of motives between the out-of-hours primary care and EMS, as well as between the GPC and MH-1813. Having obtained a response rate of $40 \%$ in our final pilot study, we aimed to send out 1000 questionnaires per health care unit. As we also aimed to compare motives for contacts regarding children and adults, we selected 1000 patients < 13 years and 1000 patients > 18 years for both the GPC and MH-1813. We selected 1100 patients rather than 1000 per EMS unit, as we expected a lower response rate and more exclusions due to high numbers of bystander calls and incorrect PINs. The data collection lasted 1 week for the two out-of-hours primary care service providers (GPC and $\mathrm{MH}-1813)$ and 2 weeks for the EMS due to differences in number of weekly patient contacts.

Data on calls were received twice a week, and questionnaires were dispatched within 4 days after the relevant out-of-hours contact to ensure vivid recall of contact details and the decision-making process. We randomly selected contacts from each health care unit, and the patient's address and status (alive/deceased) was verified in the Civil Registration System. Invitation letter and paper questionnaire were sent to patients aged $>18$ years and registered guardians for patients aged $<13$ years, including a link and login credentials to a webbased version of the questionnaire. One reminder was sent after 2 weeks. Questionnaires were sent to the patients, including for contacts initiated by bystanders. These bystander calls were assessed more common for EMS contacts, with a. 


\section{Statistical analyses}

Descriptive analyses were performed to identify the main characteristics of contacts and respondents, stratified by health care service. Motives were dichotomised into 'not important' ('not relevant', 'no importance', 'little importance', 'some importance') and 'important' ('important' and 'very important'), and the percentage of importance per motive was estimated for each of the two health care services. Aiming to identify motives for contacting the EMS (as opposed to contacting out-of-hours primary care) and to obtain risk ratios (RR), we applied the modified Poisson regression model for all contacts and stratified for children and adults [28]. The resulting RRs were presented along with 95\% confidence intervals. Moreover, a non-response analysis was conducted. Stata statistical software, version 14, was used (StataCorp LP, College Station, TX, USA).

\section{Results}

\section{Study population}

Flowchart 1 shows the selection of the population. The final response rate was $44.9 \%$ (out-of-hours primary care: $48.1 \%$ for children and $46.2 \%$ for adults; EMS: $52.1 \%$ for children and $40.4 \%$ for adults) (Fig. 1).

\section{Characteristics of respondents}

Respondent characteristics are shown in Table 1. The percentage of contacts ending with telephone advice was higher in out-of-hours primary care (children: 56.3\%; adults: $52.8 \%$ ) than in the EMS (children: $14.5 \%$; adults: $10.8 \%)$. Furthermore, differences were found for average age of adult patients (out-of-hours primary care: 49.0 years; EMS: 61.6 years) and symptom duration (out-ofhours primary care: $1-24 \mathrm{~h}$; EMS: < $1 \mathrm{~h}$ ). Furthermore, adults contacting out-of-hours primary care had more often high educational level, were more often employed and reported more often to have good health status than adults contacting the EMS.

A non-response analysis (not in Table) showed a statistically significantly different mean age between respondents and non-respondents who had contacted out-of-hours primary care (children: 3.99 vs. 3.59 years, adults: 49.0 vs. 41.0 years) and the EMS (adults: 61.6 vs.

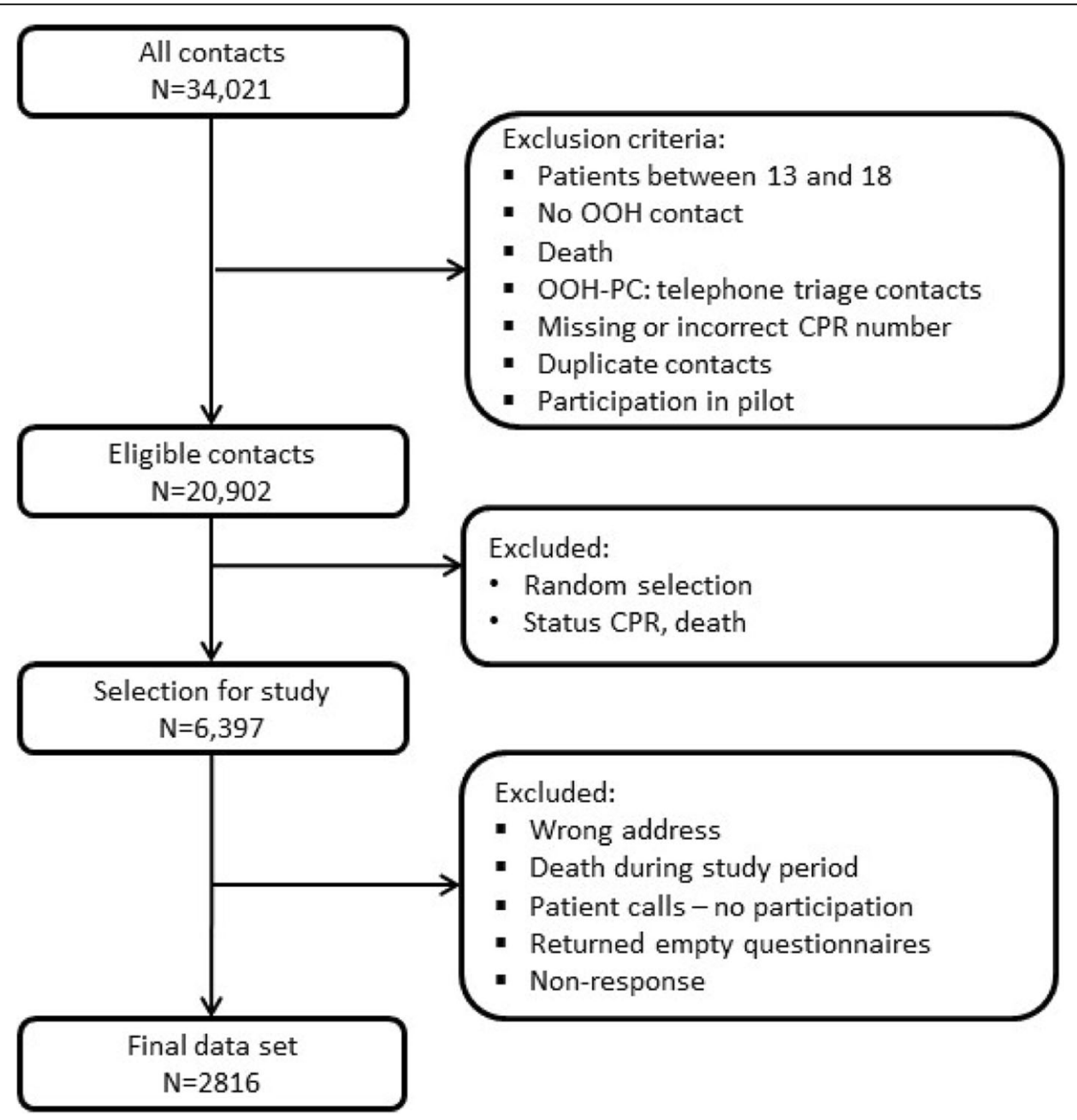

Fig. 1 Flowchart of study population 
Table 1 Description of population (\%)

\begin{tabular}{|c|c|c|c|c|}
\hline & OUT-OF-H & & EMS & \\
\hline & $\begin{array}{l}\text { Children } \\
(N=961)\end{array}$ & $\begin{array}{l}\text { Adults } \\
(N=910)\end{array}$ & $\begin{array}{l}\text { Children } \\
(N=89)\end{array}$ & $\begin{array}{l}\text { Adults } \\
(N=886)\end{array}$ \\
\hline Characteristics of contact & & & & \\
\hline Time of contact, weekend ${ }^{1}$ & 56.8 & 57.5 & 58.4 & 55.0 \\
\hline Type of contact, telephone advice & 56.3 & 52.8 & 14.5 & 10.7 \\
\hline Age patient (mean) & 4.0 & 49.0 & 3.9 & 61.6 \\
\hline Main health problem, self-assessed & $n=1342$ & $n=1084$ & $n=134$ & $n=996$ \\
\hline - Symptoms/complaints & 77.9 & 68.1 & 76.9 & 69.5 \\
\hline - Infections & 7.2 & 8.8 & 0.7 & 0.8 \\
\hline - Trauma & 4.9 & 7.6 & 13.4 & 17.8 \\
\hline - Other & 10.1 & 15.6 & 9.0 & 11.9 \\
\hline Duration of symptom & & & & \\
\hline$-<1 \mathrm{~h}$ & 14.4 & 16.1 & 94.3 & 66.1 \\
\hline$-1-24 h$ & 52.1 & 52.0 & 4.6 & 30.1 \\
\hline$->24 h$ & 33.4 & 31.9 & 1.2 & 3.8 \\
\hline Decision maker & & & & \\
\hline - Patient/parent & 97.3 & 84.5 & 89.9 & 45.0 \\
\hline - Family/other & 2.7 & 15.6 & 7.9 & 46.9 \\
\hline - Unknown & 0.0 & 0.0 & 2.3 & 8.1 \\
\hline Characteristics of patient/guardian ${ }^{2}$ & & & & \\
\hline Age (years) & & & & \\
\hline$-18-39$ & 73.9 & 36.0 & 74.4 & 16.8 \\
\hline$-40-64$ & 26.1 & 40.6 & 24.4 & 31.1 \\
\hline$->64$ & 0.0 & 23.4 & 1.2 & 52.1 \\
\hline Sex, female & 80.5 & 62.5 & 72.1 & 47.2 \\
\hline Education & & & & \\
\hline - Low & 4.9 & 15.0 & 10.8 & 26.7 \\
\hline - Middle & 34.2 & 47.7 & 31.3 & 45.6 \\
\hline - High & 60.9 & 37.3 & 57.8 & 27.7 \\
\hline Ethnicity & & & & \\
\hline - Native & 85.4 & 88.9 & 78.3 & 85.7 \\
\hline - Western migrants & 7.6 & 6.0 & 10.8 & 8.9 \\
\hline - Non-western migrants & 7.0 & 5.1 & 10.8 & 5.5 \\
\hline Marital status, single & 9.3 & 30.6 & 21.4 & 39.3 \\
\hline Employment, not working & 26.9 & 45.5 & 28.9 & 71.2 \\
\hline Health status, self-assessed, poor & 5.3 & 23.4 & 6.0 & 36.6 \\
\hline
\end{tabular}

${ }^{1}$ Day: weekend is from Friday 4 p.m. until Monday 8 a.m., week is Monday to Thursday from 4 p.m. to 8 a.m. the next day; ${ }^{2}$ For children, background information concerns parent/caregiver; Number of missing values varies per variable

53.5 year). Out-of-hours primary care non-respondents were significantly more often female than respondents (51.6\% vs. $48.4 \%)$. Calls from adult respondents to the EMS significantly more often resulted in an ambulance dispatch than calls from non-respondents $(42.2 \%$ vs. $31.5 \%)$. No difference was found for weekday, time of contact or contact type in out-of-hours primary care (face-to-face vs. telephone). Only few callers refrained from typing in their PIN when calling out-of-hours primary care E (children: 0.6\%; adults 4.4\%). At $\mathrm{MH}-1813$ and GPC, approximately one in four of callers chose to decline participation by pressing 9 (MH-1813: children: $24.2 \%$, adults: $26.0 \%$; GPC: children: $23.2 \%$, adults $29.5 \%)$.

\section{Motives for contacting}

The three most important motives were 'unpleasant symptoms', 'perceived need for prompt action' and 'perceived most suitable health care provider' (Table 2). The fourth and fifth most important motives were 'need arose outside office hours' and 'wanted to talk to a physician' for out-of-hours primary care and 'expected need for 
Table 2 Motives for contacting out-of-hours health care, stratified per setting, with the five most important motives marked in bold (\% according to importance) and adjusted risk ratio for motives associated with out-of-hours primary care contact versus EMS (RR, $95 \% \mathrm{Cl})$

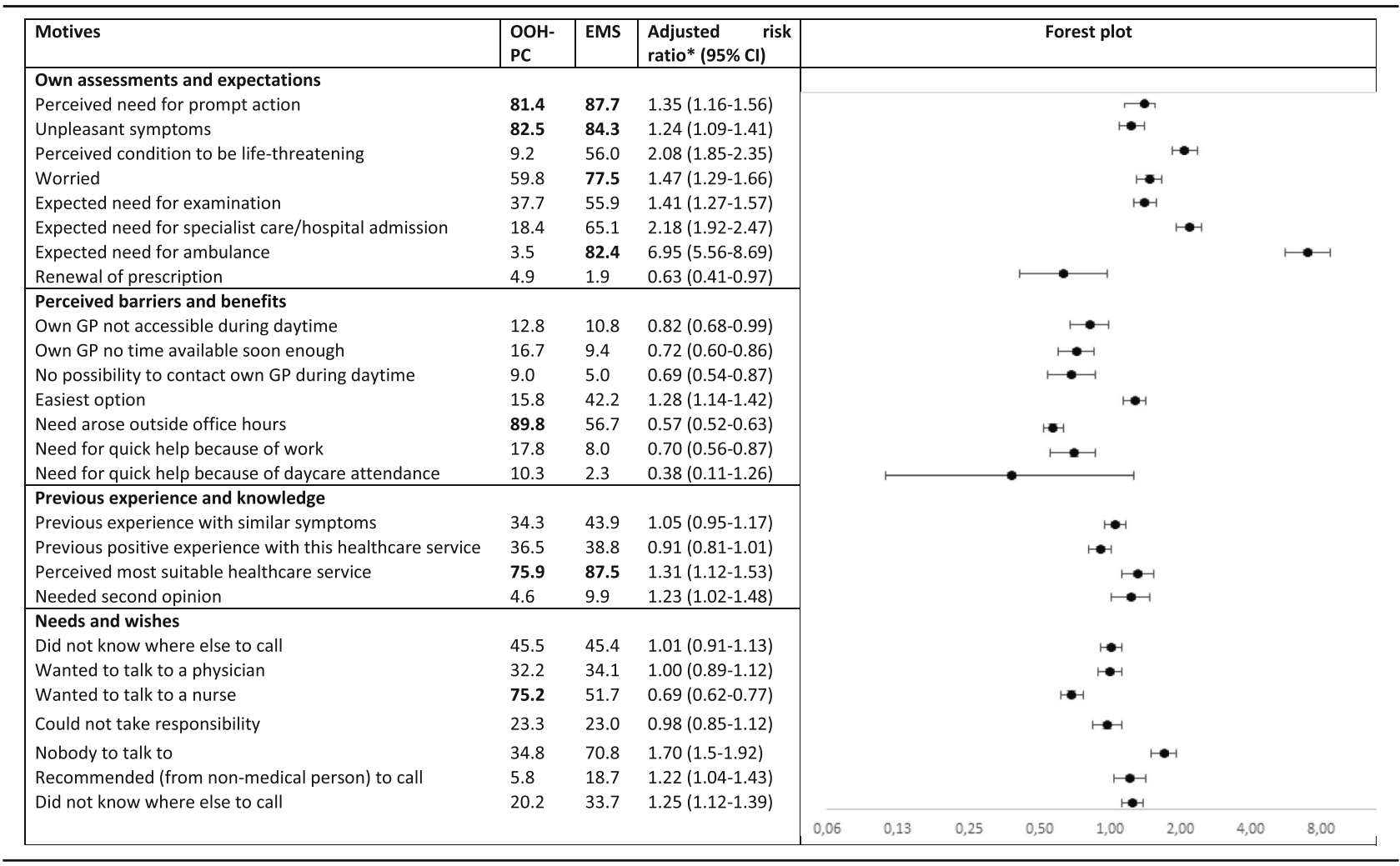

Adjusted for duration of symptom, weekend/weekday, decision-maker characteristics (age, sex, highest education level, job status, ethnicity, self-assessed health)

ambulance' and 'worried' for the EMS. For both health care service providers, the motives 'own GP not accessible during daytime' and 'own GP no time available soon enough' were also regularly mentioned (about $10 \%$ ).

\section{Factors associated with contacting out-of-hours primary care versus EMS}

Table 2 presents the adjusted RRs for motives with higher probability of contacting the EMS versus contacting out-of-hours primary care. Most motives were related to own assessment and expectations, e.g. 'perceived condition to be life-threatening' ( $R R=2.08,95 \%$ CI: 1.85-2.25) and 'expected need for ambulance' $(R R=$ 6.95, 95\% CI: 5.56-8.69). Some motives were related to previous experience and knowledge, e.g. 'perceived most suitable health care provider' ( $\mathrm{RR}=1.31,95 \% \mathrm{CI}$ : 1.12 $1-53)$ and 'needed second opinion' ( $R R=1.23,95 \% \mathrm{CI}$ : $1.02-1.48)$. Other motives were related to own needs and wishes, e.g. 'could not take responsibility' $(\mathrm{RR}=1.70$, 95\% CI: $1.50-1.92$ ), 'nobody to talk to' ( $R R=1.22,95 \%$ CI: 1.04-1.43) and 'recommended (from non-medical person) to call' ( $R R=1.25,95 \%$ CI: $1.12-1.39$ ). Some motives involved lower probability of contacting EMS versus out-of-hours primary care. Most of these motives were related to perceived barriers and benefits, e.g. 'own GP no time available soon enough' $(\mathrm{RR}=0.72,95 \% \mathrm{CI}$ : 0.60-0.86), 'no possibility to contact own GP during daytime' ( $\mathrm{RR}=0.69,95 \% \mathrm{CI}$ : $0.54-0.87)$ and 'wanted to talk to a physician' ( $R R=0.69,95 \% \mathrm{CI}: 0.62-0.77)$. The motive 'renewal of prescription' also had a lower probability ( $R R=0.63,95 \%$ CI: $0.41-0.97)$.

Figure 2 presents the adjusted RRs of motives associated with contacting either the EMS or out-of-hours primary care for health problems in children and adults. Significant differences were seen for 'perceived condition to be lifethreatening' (children: $\mathrm{RR}=3.99, \quad 95 \%$ CI: 2.75-5.79; adults: $\mathrm{RR}=1.77,95 \% \mathrm{CI}: 1.58-1.97)$, 'worried' (children: $\mathrm{RR}=6.02,95 \% \mathrm{CI}: 2.63-13.80$; adults: $\mathrm{RR}=1.27,95 \% \mathrm{CI}$ : 1.13-1.43), 'expected need for specialist care or hospital admission' (children: $\mathrm{RR}=3.29,95 \% \mathrm{CI}: 2.16-4.37$; adults: $\mathrm{RR}=1.83,95 \% \mathrm{CI}: 1.63-2.05)$ and 'need arose outside office hours' (children: $R R=0.27,95 \%$ CI: $0.20-0.37$; adults: $\mathrm{RR}=0.65$, 95\% CI: 0.59-0.72).

\section{Discussion}

\section{Key results}

Compared with the EMS, adult callers to out-of-hours primary care were younger, more often female, were 


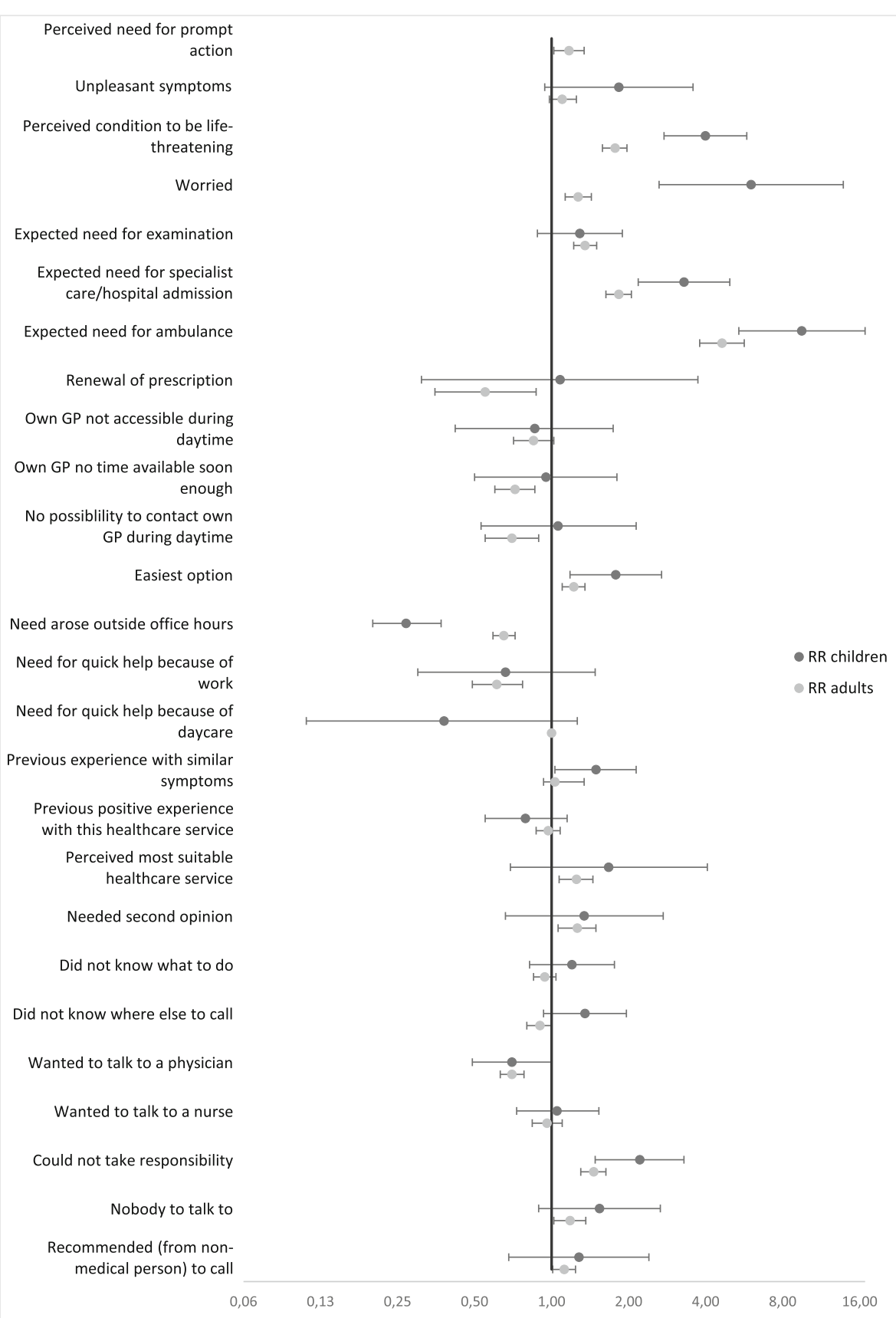

Fig. 2 Forest plot: adjusted risk ratio for motives associated with out-of-hours primary care versus EMS contacts (children and adults). Adjusted for patient (adult or child), duration of symptom, weekend/weekday, decision-maker characteristics (age, sex, highest education level, job status, ethnicity, self-assessed health)

more often employed, more often had a high educational level and self-reported more often good health status. Several motives were associated with higher probability of contacting the EMS versus contacting out-of-hours primary care. Most of these motives related to own assessment and expectations, but some motives related to previous experience and knowledge or needs and wishes. Motives associated with lower probability were mostly related to perceived barriers and benefits. Only four motives associated with contacting the EMS versus out-ofhours primary care differed significantly between children and adults.

\section{Comparison with existing literature}

To our knowledge, no previous studies have compared patients calling out-of-hours primary care and the EMS 
within one design, but several studies have investigated patients calling out-of-hours primary care [29-32]. In line with these single-service studies and clinical experiences, we found some differences between patients calling out-of-hours primary care and patients calling the EMS. As in other studies, women more often than men contacted out-of-hours primary care, and a considerable part of calls to out-of-hours primary care concerned children [29-32]. Two Danish studies on EMS contacts reported similar percentages of calls made by women, but these studies found a slightly lower mean age than found in our study $[33,34]$. This difference is likely to be due to our stratification into groups (children and adults) and exclusion of patients aged 13-18 years.

The most important motives found in our study for contacting out-of-hours primary care were partly in line with other studies. Worry and need for reassurance are frequently mentioned motives in out-of-hours primary care, as also found in other studies [12, 35, 36]. Kallestrup et al. reported that symptom relief was an important motive in about one third of contacts to outof-hours primary care [35]. Parents of Dutch children with fever have been found to contact to get reassurance from a professional [37], and a considerable part of Dutch patients have reported a perceived need to see a GP [12]. We found that perceived availability and accessibility of own GP play a role for a minority of patients, as found by Keizer et al. [12].

As far as we know, only few previous studies have focused on motives for contacting the EMS $[3,38]$. The existing studies found motives similar to the motives identified in our study. Booker et al. also reported that worry and anxiety were two important motives [3]. Furthermore, they found that callers with care responsibilities tend to contact the health care service that is expected to provide the promptest response, as decision making is driven by lower tolerance of perceived risk [3]. This result is closely related to our finding that callers could not take responsibility. In line with our findings, Ahl et al. found that the need for immediate help was an important criterion for deciding to contact ambulance care [38], and patients are aware that ambulance services provide a quick response [3]. In addition, some of the identified motives seem to match those found for patients self-referring to the ED, such as easier access to diagnostic tests and symptoms perceived to be too severe to be handled by the GP [14-17].

Patients frequently contacting out-of-hours primary care and the EMS [1-4] do not always choose the most suitable health care service provider [23, 31, 39-43], which could cause delay of care, overcrowding, overtreatment and overuse of resources. It is important to acknowledge the patient's role in the complex decisionmaking process when facing an acute health care problem. The traditional focus on medical relevance should instead be directed towards ways of assisting the patient in the decision-making process (patientcentredness). Contacting a less suitable health care service may occur because of little knowledge of available acute health care services and/or of suitable care for specific symptoms. The identified motives for calling the EMS (i.e. expectation of prompt diagnostics or need for specialist care, hospital admission or ambulance dispatch) reflect the patients' own assessment of symptoms and own care expectations, which seem in line with the more acute character of EMS. Patients make this conclusion on the basis of their knowledge of the health care system [36] and of the disease presentation.

The availability and accessibility of own GP and personal barriers ('no opportunity to call the GP', 'need for quick help because of work/daycare') could be areas of improvement, as these motives were mentioned by patients at both health care services. Several other studies have shown an association between the accessibility of own GP and use of out-of-hours primary care [36, 44]; this association may also be relevant for EMS contacts. In our study, most patients stated that their need emerged outside the opening hours of their own GP. The need to contact health care may truly have appeared outside the opening hours [45], but the answers could also have been biased by social desirability. Parents may find it difficult to decide whether to contact out-ofhours primary care for a health problem occurring outside office hours or wait until the opening hours of own GP [36], whereas GPs may find that patients have a low threshold for contacting out-of-hours care [46].

\section{Strengths and limitations}

We conducted a large-scale study exploring patient characteristics and motives to contact the out-of-hours health care services in two Danish regions, with parallel data collection at out-of-hours primary care and the EMS. The developed questionnaire was found to have good face and content validity, and three small-scale pilot studies ensured further optimisation. Based on literature and feedback from experts and patients, we acquired a thorough overview of relevant patient motives for contacting out-of-hours care. Yet, our studies also had some limitations.

We cannot rule out selection bias, even though our response rate $(44.9 \%)$ was acceptable for this type of study. The non-response analysis showed that some characteristics differed between our respondents and nonrespondents. This may have influenced our results on important motives for contacting out-of-hours care, as some motives related to specific patient groups. A considerable drop-out rate was seen at out-of-hours primary care as some patients declined participation. We 
predefined 26 motives that were considered relevant for contacting out-of-hours care and asked the respondents to assess their importance. Thus, the patients could point out multiple relevant motives, without ranking the most important ones. This approach allowed us to consider the impact of all motives, including the ones perceived as less important, which is relevant for the understanding of the decision-making process in patients. Our list of 26 predefined motives may not be complete, thus introducing some bias. Yet, as our list was defined after an extensive procedure, we expect this bias to be minimal. Primarily, we studied the motives underlying decision-making, without assessing suitableness or patient outcome. However, we could not rule out social desirability bias, as patients may have wanted to give suitable and acceptable motives for their contact and the received health care. We included all contacts, including bystander calls to EMS. As questionnaires were answered by patients, some information bias may appear for bystander calls. Yet, most calls were made by family members or other known bystanders. Finally, generalisation of findings to other populations in similar health care systems should be made with caution, as the access to both out-of-hours primary care and the EMS is free of charge in Denmark and access is by telephone call.

\section{Recommendations for future research and clinical practice}

Our study contributes to understanding the complex decision-making process of patients in need of acute health care. This knowledge may contribute to suitable adjustment of the existing health care services, aiming to optimise patient safety and service level without increasing health care costs. Previous studies have found that patients do not always access the most suitable service, which could be caused by a range of factors. Future studies focusing on the identified motives seem relevant, such as the importance of the availability and accessibility of own GP for the decision to contact out-of-hours primary care and the potential effect of ensuring better availability and accessibility. Furthermore, an international comparison could be interesting, giving the opportunity to study different organizational and health care system factors in relation to motives for help seeking. Moreover, patients could be assisted by public information campaigns on available health care services and target groups, and the effects of creating one access point to acute care could be explored.

\section{Conclusions}

We identified five key patient motives for seeking acute health care at out-of-hours primary care and the EMS; some of these motives were partly overlapping (i.e. 'unpleasant symptoms', 'perceived need for prompt action' and 'perceived most suitable health care provider'). Several factors were associated with contacting OOH-PC versus EMS. Most motives relating to own assessment and expectations, previous experience and knowledge, and own needs and wishes were related to a higher probability of contacting EMS versus out-of-hours primary care, whereas most motives relating to perceived barriers and benefits were related to a lower probability. This knowledge could contribute to adjustments of the current health care services, with the aim to optimise patient safety and service level without increasing health care costs.

\section{Supplementary information}

Supplementary information accompanies this paper at https://doi.org/10. 1186/s12873-020-00312-3.

Additional file 1. Questionnaire "Why did you contact the out-of-hours service?"

Additional file 2. Abbreviation list of the motives.

\section{Abbreviations}

1-1-2: The emergency number 1-1-2; 95\% Cl: 95\% confidence interval; ED: Emergency department; GP: General practitioner; GPC: GP cooperative; MH-1813: Medical helpline 1813; RR: Risk ratio

\section{Acknowledgements}

We would like to thank the respondents for completing the questionnaire. We would also like to thank the staff from the GPC and the EMS in the Central Denmark Region as well as the staff from $\mathrm{MH}-1813$ and the EMS in Copenhagen for their extensive help with the selection of contacts for the data collection.

\section{Authors' contributions}

LH designed the study and the questionnaire, collected, analysed and interpreted the data, and drafted the manuscript. AHC participated in the design of the study, the development of the questionnaire, analyses and interpretation of the data, and gave feedback on the manuscript. GM participated in the design of the study and of the questionnaire and gave feedback on the manuscript. HCC gave feedback on the interpretation of the data and the manuscript. IS gave feedback on the design of the study and the questionnaire, interpretation of the data and the manuscript. MBC participated in the design of the study and questionnaire, interpretation of the data and contributed to the manuscript. All authors read and approved the final version of the manuscript.

\section{Funding}

This study was supported by the Danish foundation TrygFonden (file no. 7 12-1056). TrygFonden had no role in the design of the study, in the collection, analysis and interpretation of data, or in the writing of the manuscript.

\section{Availability of data and materials}

The datasets used and analysed as part of this study are available from the corresponding author on reasonable request.

\section{Ethics approval and consent to participate}

The project was approved by the Danish Data Protection Agency (J.no. 2011-416365) and by the Danish Health Authority (J.no. 3-3013-445/1). The Danish Health Authority approved use of patient contact information of the included settings to send questionnaires, requiring an information letter that explicitly stated the option to decline participation and the option to request removal of all personal information. In addition, the researchers, GPC and $\mathrm{MH}-1813$ chose to add an option to decline participation for patients calling. A recorded message on the telephone waiting line informed patients calling the GPC and $\mathrm{MH}-1813$ 
about the ongoing research project, and callers were given the opportunity to decline participation by pressing ' 9 '. Due to the urgent character of calls and limited telephone waiting time, this was not deemed feasible at EMS. According to Danish law (i.e. the Act on Research Ethics Review of Health Research Projects, Act number 593 of 14 July 2011, section 14(2)) notification of questionnaire surveys and medical database research projects to the system of research ethics committee system is only required if the project involves human biological material. Thus, approval from the Committee on Health Research Ethics was not required as no biomedical intervention was performed in this study.

\section{Consent for publication}

Not applicable.

\section{Competing interests}

The authors declare that they have no competing interests.

\section{Author details}

${ }^{1}$ Research Unit for General Practice, Bartholins Alle 2, 8000 Aarhus, Denmark. ${ }^{2}$ Emergency Medical Services, Telegrafvej 5, 2750, Ballerup, Denmark. ${ }^{3}$ Danish Clinical Quality Program (RKKP), Frederiksberg Hospital, Ndr. Fasanvej 57, 2000, Frederiksberg, Denmark. ${ }^{4}$ Prehospital Emergency Medical Services, Central Denmark Region, Olof Palmes Allé 34, 8200 Aarhus, N, Denmark.

\section{Received: 23 May 2019 Accepted: 19 February 2020}

Published online: 17 March 2020

\section{References}

1. Carter EJ, Pouch SM, Larson EL. The relationship between emergency department crowding and patient outcomes: a systematic review. J Nurs Scholarsh. 2014;46:106-15.

2. Lowthian JA, Cameron PA, Stoelwinder JU, Curtis A, Currell A, Cooke MW, et al. Increasing utilisation of emergency ambulances. Aust Health Rev. 2011:35:63-9.

3. Booker MJ, Simmonds RL, Purdy S. Patients who call emergency ambulances for primary care problems: a qualitative study of the decisionmaking process. Emerg Med J. 2014;31:448-52.

4. Smits M, Rutten M, Keizer E, Wensing M, Westert G, Giesen P. The development and performance of after-hours primary care in the Netherlands: a narrative review. Ann Intern Med. 2017;166:737-42.

5. Smits M, Keizer E, Huibers L, Giesen P. GPs' experiences with out-of-hours GP cooperatives: a survey study from the Netherlands. Eur J Gen Pract. 2014:20:196-201.

6. Hoot NR, Aronsky D. Systematic review of emergency department crowding: causes, effects, and solutions. Ann Emerg Med. 2008:52:126-36.

7. Billings J, Parikh N, Mijanovich T. Emergency department use: the New York Story. Issue Brief (Commonw Fund). 2000;434:1-12

8. Mehrotra A, Wang MC, Lave JR, Adams JL, McGlynn EA. Retail clinics, primary care physicians, and emergency departments: a comparison of patients' visits. Health Aff (Millwood). 2008;27:1272-82.

9. O'Malley AS, Samuel D, Bond AM, Carrier E. After-hours care and its coordination with primary care in the U.S. J Gen Intern Med. 2012;27:1406-15.

10. Moll van Charante EP, van Steenwijk-Opdam PC, Bindels PJ. Out-of-hours demand for GP care and emergency services: patients' choices and referrals by general practitioners and ambulance services. BMC Fam Pract. 2007:8:46.

11. Johnson KD, Winkelman C. The effect of emergency department crowding on patient outcomes: a literature review. Adv Emerg Nurs J. 2011;33:39-54.

12. Keizer $E$, Smits M, Peters $Y$, Huibers $L$, Giesen $P$, Wensing $M$. Contacts with out-of-hours primary care for nonurgent problems: patients' beliefs or deficiencies in healthcare? BMC Fam Pract. 2015;16:157-015-0376-9.

13. Hugenholtz M, Broer C, van Daalen R. Apprehensive parents: a qualitative study of parents seeking immediate primary care for their children. $\mathrm{Br} J \mathrm{Gen}$ Pract. 2009;59:173-9.

14. Lega F, Mengoni A. Why non-urgent patients choose emergency over primary care services? Empirical evidence and managerial implications Health Policy. 2008;88:326-38.

15. Kraaijvanger N, Rijpsma D, van Leeuwen H, Edwards M. Self-referrals in the emergency department: reasons why patients attend the emergency department without consulting a general practitioner first-a questionnaire study. Int J Emerg Med. 2015;8:46.
16. Moll van Charante EP, ter Riet G, Bindels P. Self-referrals to the A\&E department during out-of-hours: patients' motives and characteristics. Patient Educ Couns. 2008;70:256-65.

17. Schmiedhofer M, Mockel M, Slagman A, Frick J, Ruhla S, Searle J. Patient motives behind low-acuity visits to the emergency department in Germany: a qualitative study comparing urban and rural sites. BMJ Open. 2016;6: e013323.

18. Thijssen WA, van Mierlo E, Willekens M, Rebel J, Sandel MH, Giesen P, et al. Complaints and diagnoses of emergency department patients in the Netherlands: a comparative study of integrated primary and emergency care. PLoS One. 2015;10:e0129739.

19. Chmiel C, Wang M, Sidler P, Eichler K, Rosemann T, Senn O. Implementation of a hospital-integrated general practice - a successful way to reduce the burden of inappropriate emergency-department use. Swiss Med Wkly. 2016; 146:w14284

20. Uscher-Pines L, Pines J, Kellermann A, Gillen E, Mehrotra A. Emergency department visits for nonurgent conditions: systematic literature review. Am J Manag Care. 2013;19:47-59.

21. Durand AC, Gentile S, Devictor B, Palazzolo S, Vignally P, Gerbeaux P, et al. ED patients: how nonurgent are they? Systematic review of the emergency medicine literature. Am J Emerg Med. 2011:29:333-45.

22. Huibers L, Moth G, Carlsen AH, Christensen MB, Vedsted P. Telephone triage by GPs in out-of-hours primary care in Denmark: a prospective observational study of efficiency and relevance. Br J Gen Pract. 2016;66: e667-73.

23. Smits $M$, Francissen $O$, Weerts $M$, Janssen $K$, van Grunsven $P$, Giesen $P$. Emergency ambulance call-outs often provide primary care. Ned Tijdschr Geneeskd. 2014;158:A7863.

24. Olesen F, Jolleys JV. Out of hours service: the Danish solution examined. BMJ. 1994:309:1624-6.

25. Andersen MS, Johnsen SP, Sorensen JN, Jepsen SB, Hansen JB, Christensen EF. Implementing a nationwide criteria-based emergency medical dispatch system: a register-based follow-up study. Scand J Trauma Resusc Emerg Med. 2013;21:53.

26. Pedersen CB. The Danish civil registration system. Scand J Public Heal. 2011; 39:22-5

27. Andersen R, Newman JF. Societal and individual determinants of medical care utilization in the United States. Milbank Mem Fund Q Health Soc. 1973; 51:95-124.

28. Zou G. A modified poisson regression approach to prospective studies with binary data. Am J Epidemiol. 2004;159:702-6.

29. Buja A, Toffanin R, Rigon S, Sandona P, Carraro D, Damiani G, et al. Out-ofhours primary care services: demands and patient referral patterns in a Veneto region (Italy) local health authority. Health Policy. 2015;119:437-46.

30. Huibers LA, Moth G, Bondevik GT, Kersnik J, Huber CA, Christensen MB, et al. Diagnostic scope in out-of-hours primary care services in eight European countries: an observational study. BMC Fam Pract. 2011;12:30

31. Welle-Nilsen LK, Morken T, Hunskaar S, Granas AG. Minor ailments in out-ofhours primary care: an observational study. Scand J Prim Health Care. 2011; 29:39-44.

32. Giesen $P$, Franssen E, Mokkink H, van den Bosch W, van Vugt A, Grol R. Patients either contacting a general practice cooperative or accident and emergency department out of hours: a comparison. Emerg Med J. 2006;23:731-4.

33. Christensen EF, Larsen TM, Jensen FB, Bendtsen MD, Hansen PA, Johnsen SP, et al. Diagnosis and mortality in prehospital emergency patients transported to hospital: a population-based and registry-based cohort study. BMJ Open. 2016;6:e011558.

34. Christensen EF, Bendtsen MD, Larsen TM, Jensen FB, Lindskou TA, Holdgaard $\mathrm{HO}$, et al. Trends in diagnostic patterns and mortality in emergency ambulance service patients in 2007-2014: a population-based cohort study from the North Denmark region. BMJ Open. 2017;7:e014508.

35. Kallestrup P, Bro F. Parents' beliefs and expectations when presenting with a febrile child at an out-of-hours general practice clinic. Br J Gen Pract. 2003; $53: 43-4$

36. Lass M, Tatari CR, Merrild CH, Huibers L, Maindal HT. Contact to the out-ofhours service among Danish parents of small children - a qualitative interview study. Scand J Prim Health Care. 2018;36:216-23.

37. de Bont EG, Loonen N, Hendrix DA, Lepot JM, Dinant GJ, Cals JW. Childhood fever: a qualitative study on parents' expectations and experiences during general practice out-of-hours care consultations. BMC Fam Pract. 2015;16:131. 
38. Ahl C, Nystrom M, Jansson L. Making up one's mind:--patients' experiences of calling an ambulance. Accid Emerg Nurs. 2006;14:11-9.

39. Noroxe KB, Huibers L, Moth G, Vedsted P. Medical appropriateness of adult calls to Danish out-of-hours primary care: a questionnaire-based survey. BMC Fam Pract. 2017;18:34.

40. Moth G, Huibers L, Ovesen A, Christensen MB, Vedsted P. Preschool children in out-of-hours primary care - a questionnaire-based cross-sectional study of factors related to the medical relevance of health problems. BMC Fam Pract. 2017;18:112

41. Snooks H, Wrigley H, George S, Thomas E, Smith H, Glasper A. Appropriateness of use of emergency ambulances. J Accid Emerg Med. 1998;15:212-5

42. Grusd E, Kramer-Johansen J. Does the Norwegian emergency medical dispatch classification as non-urgent predict no need for pre-hospital medical treatment? An observational study Scand J Trauma Resusc Emerg Med. 2016;24:65

43. Lehm KK, Andersen MS, Riddervold IS. Non-urgent emergency callers: characteristics and prognosis. Prehosp Emerg Care. 2017;21:166-73.

44. Smits M, Peters Y, Broers S, Keizer E, Wensing M, Giesen P. Association between general practice characteristics and use of out-of-hours GP cooperatives. BMC Fam Pract. 2015;16:52.

45. Houston AM, Pickering AJ. Do I don't I call the doctor': a qualitative study of parental perceptions of calling the GP out-of-hours. Health Expect. 2000;3 234-42.

46. Smith H, Lattimer V, George S. General practitioners' perceptions of the appropriateness and inappropriateness of out-of-hours calls. Br J Gen Pract. 2001;51:270-5.

\section{Publisher's Note}

Springer Nature remains neutral with regard to jurisdictional claims in published maps and institutional affiliations.

Ready to submit your research? Choose BMC and benefit from:

- fast, convenient online submission

- thorough peer review by experienced researchers in your field

- rapid publication on acceptance

- support for research data, including large and complex data types

- gold Open Access which fosters wider collaboration and increased citations

- maximum visibility for your research: over $100 \mathrm{M}$ website views per year

At BMC, research is always in progress.

Learn more biomedcentral.com/submissions 